\title{
Does routine home visiting improve the return rate and outcome of DOTS patients who delay treatment?
}

\author{
A. Mohan, ${ }^{1}$ H. Nassir ${ }^{2}$ and A. Niazi ${ }^{3}$ \\ هل تحسن الزيارات المنزلية الروتينية نسب العودة للمعالمحة القصيرة الأمد تحت الإشراف المباشر

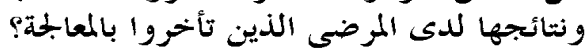

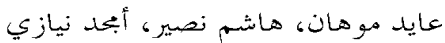

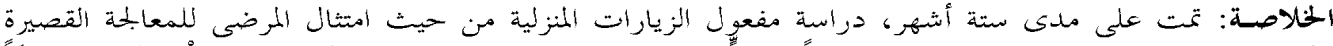

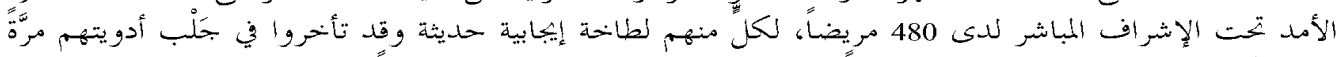

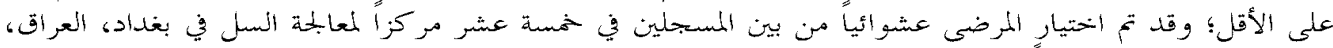

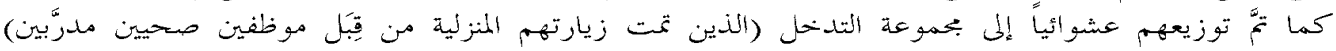

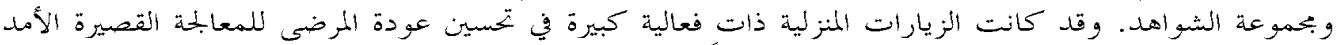

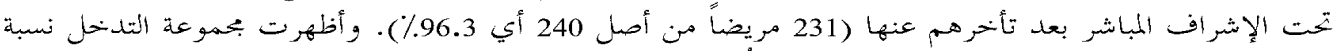

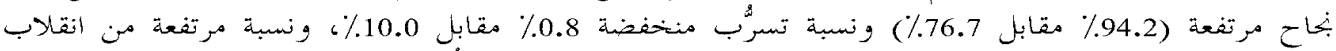

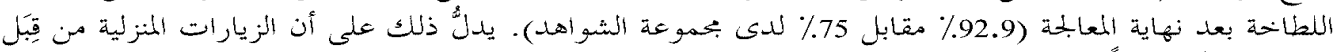

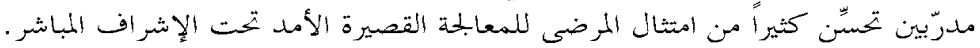

ABSTRACT Over a period of 6 months the effect of home visits on compliance with directly observed therapy, short course (DOTS), was studied on 480 new smear-positive tuberculosis patients who had delayed collecting their drugs on one occasion. Patients registered at 15 tuberculosis treatment centres in Baghdad, Iraq, were randomized to an intervention group (receiving home visits from trained personnel) or a control group. Home visits were highly effective in improving the return to treatment of patients who were late for treatment $(231 / 240,96.3 \%)$. The intervention group showed a higher treatment success rate $(94.2 \%$ versus $76.7 \%)$, lower default rate $(0.8 \%$ versus $10.0 \%)$ and higher smear conversion rate after the end of treatment $(92.9 \%$ versus $75.0 \%)$ than controls. Home visiting by trained personnel significantly improves patient compliance with DOTS.

\begin{abstract}
Les visites régulières à domicile améliorent-elles le taux de retour au traitement et l'évolution des patients sous traitement DOTS qui sont en retard dans leur traitement?

RESUME Sur une période de 6 mois, l'effet des visites à domicile sur l'observance du traitement de courte durée sous surveillance directe (DOTS) a été étudié chez 480 nouveaux patients atteints de tuberculose à frottis positif qui étaient venus chercher leurs médicaments en retard au moins une fois. Les patients enregistrés dans 15 centres de traitement de la tuberculose à Bagdad (Iraq) ont été randomisés en deux groupes : un groupe recevant les visites à domicile d'un personnel qualifié ou groupe de l'intervention et un groupe témoin. Les visites à domicile ont été très efficaces pour améliorer le retour au traitement des patients qui étaient en retard dans la prise du traitement (231/240, 96,3\%). Dans le groupe de l'intervention, le taux de réussite du traitement était plus élevé ( $94,2 \%$ contre $76,7 \%)$, le taux d'abandon plus bas $(0,8 \%$ contre $10,0 \%)$ et le taux de conversion du frottis après la fin du traitement (92,9\% contre $75,0 \%)$ plus élevé que dans le groupe témoin. Les visites à domicile effectuées par un personnel qualifié améliorent sensiblement l'observance du DOTS par les patients.
\end{abstract}

${ }^{1}$ Directorate General of Preventive Medicine, Ministry of Health, Baghdad, Iraq.

${ }^{2}$ Institute of Tuberculosis and Chest Disease, Baghdad, Iraq.

${ }^{3}$ Department of Community Medicine, Al Nahrain Medical College, Baghdad, Iraq.

المجلة الصحية لشرق المتوسط، منظمة الصحة العالمية، المجلد التاسع، العدد ع، ب... 


\section{Introduction}

Tuberculosis (TB) is an increasingly serious disorder worldwide [1]. Mycobacterium tuberculosis causes around 3 million deaths annually, more than that caused by any other single pathogen. TB control policies emphasize the importance of casefinding and treatment, particularly of smear-positive cases, aiming for a cure rate of $85 \%$ [2]. Directly observed treatment, short course (DOTS), is a strategy for TB care that includes improved drug supply, diagnosis and programme monitoring and a 6-month multidrug regimen with direct observation to ensure that the drugs have been taken to improve treatment adherence and outcome [1]. Successful completion of treatment by active cases of TB is the single most important way to control and prevent new cases. However, treatment completion is often delayed or unsuccessful because it requires that patients adhere to medication for at least 6 months [3].

The role of home visiting and supervision of DOTS by a non-governmental organization (NGO) in a TB programme was studied in Nepal. Information collected on home visits to a cohort of 205 smear-positive patients showed that almost one-third of new smear positive cases were visited, and $14 \%$ of patients required home visits to ensure treatment completion [4]. A study in Switzerland of patients treated by independent practitioners [5] showed that the success rate was $70 \%$, the defaulter rate was $16 \%$ and the death rate $14 \%$. Compliance with DOTS in the Kota Kinabalu area of Malaysia was affected by travel expenses, time spent travelling to treatment centres and having family members who have had the disease [6].

In Iraq, TB in a major public health problem and there has been a $50 \%$ increase in the notification rate during the last 4 years to a current rate of 135 per 100000 population [4]. The proportion of patients defaulting from treatment in Iraq is $10 \%$ and the proportion who delay coming for treatment is $20 \%$ [4]. The usual practice in Iraq for tracing patients who delay coming for treatment is to contact them by telephone at home but if they have no telephone no other action is taken. It would be preferable to institute a system of home visits for tracing all patients who delay treatment, but the resources are not currently available and could be obtained only if there is convincing evidence of the effectiveness of the system.

The aims of this study were to investigate the effect of home visiting on the return to treatment and on the treatment outcomes of patients who delayed attendance for treatment.

\section{Methods}

\section{Study design}

This study was designed to randomize patients into either intervention (visited at home) or control (not visited) groups. To detect a frequency of patients of $10 \%-20 \%$ with a $95 \%$ confidence level and statistical power of $80 \%$ we needed a sample size of 219 in each group. Adding 10\% for nonparticipation meant that a sample of 240 was needed.

\section{Selection of subjects}

The study subjects were 480 new smearpositive patients with pulmonary TB who had never been treated previously and who delayed coming to collect their drugs at the health centre for at least 3 days after the scheduled appointment. Patients were identified by the district TB coordinator from official patient record cards. Smear-positive cases were selected because of their

المجلة الصحية لشرق المتوسط، منظمة الصحة العالمية، المجلد التاسع، العدد ؟، ب... 
role in spreading infection and because treatment outcome can be easily evaluated by checking smear conversion rates. Retreatment patients (defaulters) were excluded because the number of cases is smaller.

Equal number of patients were randomly allocated to the control or intervention group after the first episode of delaying. If any patient delayed attending for treatment subsequent to this episode, follow-up was according to the initial randomization. Subsequent episodes of delay were recorded but not used as part of the definition.

Blinding of the selection was impossible, as the intervention was known to patients. However, the patients were not told about the alternative method used for follow-up. The evaluation was blind as the information about outcome was collected by a field worker who did not know which group the patients was assigned to.

\section{Data collection}

The study was started in May 2001 in 15 health centres in Baghdad, randomly chosen from a list of all centres in Baghdad. The main study enrolment was for 6 months with 6-months follow-up.

The control group received no visits. The intervention patients received visits at home from a local volunteer in order to motivate them to attend the health centre daily. We selected and trained 15 women from a local NGO, the Iraqi Women's Federation and assigned each to a TB centre coverage area. All the women were from the same district where the study was conducted and all were volunteers who received no payment except an allowance for transport. When a patient was recorded as late for collection of drugs, a woman was assigned to visit the patient at home and ask him/her to return to the centre. Home visi- tors also carried out health education for the patient and his/her family. If the patient was not at home, the volunteer returned another time and, if the patient refused to attend, she would try to convince him/her with the help of the family to report to the TB coordinator at the centre. The home visitors were trained under the guidance of the TB coordinator. They received standardized instructions and were assessed in a pilot study before the start of the main study. A record of visits to the patient was made on a separate sheet and not on the patient record.

Patients' attendance for treatment was noted from the TB centre records. A special data collection form was used to record basic information about each patient (age, sex, address), date of diagnosis and date of starting treatment. The results of sputum examination were recorded for the following stages: before treatment, after the second month of treatment, at the fifth month and at the end of treatment. All patients were followed until they had completed treatment according to the records from the TB register and patient's treatment cards at the TB centre. The final outcome of treatment after the end of 6 months follow-up was classified using WHO definitions: treatment success (patient who completes treatment and is cured), default (treatment interrupted for 2 consecutive months or more), treatment failure (patient who is sputum positive at 5 months or later during treatment) or death.

The TB coordinators (1 per district) were trained about the study design and how to identify latecomers, instruct the home visitors and carry out the follow-up. Another field worker was identified and trained to fill in the data collection forms. To reduce the possibility of bias the field worker did not know whether or not the

المجلة الصحية لشرق المتوسط، منظمة الصحة العالمية، المجلد التاسع، العدد ع، ب... 
patient was visited. The average distance from patients' houses to the TB centre was calculated and was not significantly different between the 2 groups.

The study was carried out after receiving ethical clearance from the Ministry of Health and confidentiality was maintained by not identifying the home visitor as a TB worker. All personal information was kept strictly confidential.

\section{Data analysis}

Data was entered into Epi-info, version 5. We compared treatment completion in the intervention and control groups by the chisquared test or logistic regression analysis, with completion of treatment as the dependent and home visiting as the independent variable. The return of latecomers and the treatment success rates with and without home visiting were analysed using the chisquared test.

\section{Results}

After the second month of treatment $85.0 \%$ of the intervention group and $66.7 \%$ of the control group had converted to smear negative $(P<0.001)$ (Table 1$)$. There were also statistically significant differences between the intervention and control groups in terms of smear conversion after the fifth month and after the end of treatment.

Table 2 shows a statistically significant effect of the intervention on the proportion of patients returning to treatment, with $96.3 \%$ of patients returning for treatment in the home visit group compared with $82.5 \%$ in the control group. There was also a highly significant association between home visiting and treatment success: $94.2 \%$ of home visit patients compared with $76.7 \%$ of the controls. Table 2 shows a highly significant association between home visiting and the default rate with only $0.8 \%$ of the intervention patients defaulting on treatment compared with $10.0 \%$ in the control group.

The home visit group had a lower treatment failure rate than controls but the difference was not statistically significant $(P$ $=0.06$ ) (Table 2). Similarly, there were slightly fewer deaths in the intervention group ( $n=3,1.3 \%)$ than controls $(n=8$, $3.3 \%$ ), but the difference was not significant. Table 1 Comparison of smear conversion rates at different stages of tuberculosis
treatment between control and intervention groups

\begin{tabular}{|c|c|c|c|c|c|}
\hline \multirow[t]{2}{*}{ Smear conversion } & \multicolumn{2}{|c|}{$\begin{array}{l}\text { Home visit patients } \\
\qquad(n=240)\end{array}$} & \multicolumn{2}{|c|}{$\begin{array}{l}\text { Control patients } \\
\quad(n=240)\end{array}$} & \multirow[t]{2}{*}{ Significance } \\
\hline & No. & $\%$ & No. & $\%$ & \\
\hline Negative after 2nd month & 204 & 85.0 & 160 & 66.7 & $\chi^{2}=22.01, P<0.001$ \\
\hline Positive after 2nd month & 36 & 15.0 & 80 & 33.3 & $\chi^{2}=13.51, P<0.001$ \\
\hline Negative after 5th month & 216 & 90.0 & 172 & 71.7 & $\chi^{2}=26.03, P<0.001$ \\
\hline $\begin{array}{l}\text { Negative after end of } \\
\text { treatment }\end{array}$ & 223 & 92.9 & 180 & 75.0 & $\chi^{2}=28.60, P<0.001$ \\
\hline
\end{tabular}

$\mathrm{n}=$ total number of patients. 


\begin{tabular}{|c|c|c|c|c|c|}
\hline \multirow[t]{2}{*}{ Indicator } & \multicolumn{2}{|c|}{$\begin{array}{l}\text { Home visit patients } \\
\qquad(n=240)\end{array}$} & \multicolumn{2}{|c|}{$\begin{array}{l}\text { Control patients } \\
\quad(n=240)\end{array}$} & \multirow[t]{2}{*}{ Significance $^{a}$} \\
\hline & No. & $\%$ & No. & $\%$ & \\
\hline \multicolumn{6}{|c|}{ Return for treatment } \\
\hline Yes & 231 & 96.3 & 198 & 82.5 & $\chi^{2}=22.47, P<0.001$ \\
\hline No & 9 & 3.8 & 42 & 17.5 & \\
\hline \multicolumn{6}{|c|}{ Treatment success } \\
\hline Yes & 226 & 94.2 & 184 & 76.7 & $\chi^{2}=28.11, P<0.001$ \\
\hline No & 14 & 5.8 & 56 & 23.3 & \\
\hline \multicolumn{6}{|l|}{ Default } \\
\hline Yes & 2 & 0.8 & 24 & 10.0 & $\chi^{2}=17.93, P<0.001$ \\
\hline No & 238 & 99.2 & 216 & 90.0 & \\
\hline \multicolumn{6}{|c|}{ Treatment failure } \\
\hline Yes & 5 & 2.1 & 14 & 5.8 & $\chi^{2}=3.51, P=0.06$ \\
\hline No & 235 & 97.9 & 226 & 94.2 & \\
\hline \multicolumn{6}{|l|}{ Death } \\
\hline Yes & 3 & 1.3 & 8 & 3.3 & $\chi^{2}=1.49, P=0.222$ \\
\hline No & 237 & 98.8 & 232 & 96.7 & \\
\hline
\end{tabular}

ayates $\chi^{2}$.

$\mathrm{n}=$ total number of patients.

\section{Discussion}

From numerous studies and experience in various situations, it is now widely accepted that the most important cause of failure in TB treatment programmes is irregular drug taking by patients, which is a direct consequence of poor motivation [8]. It has also been accepted that the primary focus of motivation should be the programme staff [9]. A successful, cost-effective, community-based programme of directly observed therapy, utilizing volunteers, clinic and community health workers, can help ensure adherence to therapy [10].

This study was designed to reveal the effect of home visiting on patients who delayed attendance for treatment compared with the conventional DOTS programme. The DOTS method ensures that the patient actually takes the medication under direct supervision of an assistant and has emerged as probably the best solution to the problem of non-compliance. It has been proven effective in various part of the world [11-13]. It is clear from the findings of this study that home visiting of patients with TB definitely had an impact on the return of treatment delayers to continue their medication and the results were better than the conventional method of DOTS [14]. Out of 240 patients, 231 (96.3\%) returned, a better result than a study carried out in Korea [15].

Our study showed that home visiting had an important role in improving the treatment outcome of new smear-positive pulmonary TB patients who were late for treatment. The treatment success rate was significantly much higher in the intervention group $(94.3 \%)$ compared with the 
control group (76.7\%). The defaulter rate in the intervention group was also much improved: the defaulter rate in the intervention group was only $0.8 \%$ versus $10.0 \%$ in the control group. The treatment failure rate was not significantly affected, however, with $2.1 \%$ of patients in the intervention group failing treatment compared with $5.8 \%$ in the control group. A large Chinese study of 112842 patients showed that with DOTS the failure rate was $6.2 \%$ [16]. The death rate in our study was also reduced but not significantly so: $1.3 \%$ in the intervention group and $3.3 \%$ in the control group.

There was a highly significant difference in the smear conversion rate of patients, which was better in the intervention group (92.9\% at the end of treatment) than the control group (75.0\%).

\section{Conclusions}

We conclude from this study that home visiting by trained personnel significantly improves the compliance of patients who delayed attendance for treatment as well as their treatment success rate, smear conversion rate and defaulter rate. Research on the cost-effectiveness of this intervention is recommended in order to provide additional evidence about the importance of its introduction within DOTS strategy in lowincome countries with a high burden of TB.

\section{Acknowledgements}

This investigation received technical and financial support from the joint WHO Eastern Mediterranean Region (EMRO), Division of Communicable Diseases (DCD) and the WHO Special Programme for Research and Training in Tropical Diseases (TDR): the EMRO/DCD/TDR Small Grants Scheme for Operational Research in Tropical and Communicable Diseases.

\section{References}

1. Use DOTS more widely: WHO report on the tuberculosis epidemic 1997. Geneva, WHO, 1997 (WHO/TB/97.224).

2. Kochi A. The global tuberculosis situation and the new control strategy of the World Health Organization. Tubercle, 1991, 72:1-6.

3. Bass JB. Treatment of tuberculosis and tuberculosis infection in adults and children. American Thoracic Society and the Centers for Disease Control and Prevention. American journal of respiratory and critical care medicine, 1994, 149: 1359-74.

4. White AJ, Robinson-White CM, Luitel $\mathrm{H}$. A report on home visiting practices con- ducted in remote districts of Nepal in an NGO-run tuberculosis control programme. International journal of tuberculosis and lung disease, 1999, 3(6): 534-6.

5. Zellweger JP, Coulon P. Outcome of patients treated for tuberculosis in Vaud County, Switzerland. International journal of tuberculosis and lung disease, 1998, 2(5):372-7.

6. O'Boyle SJ et al. Factors affecting patient compliance with anti-tuberculosis chemotherapy using directly observed treatment, short-course strategy (DOTS). International journal of tuberculosis and lung disease, 2002, 6(4):307-12.

المجلة الصحية لشرق المتوسط، منظمة الصحة العالمية، المجلد التاسع، العدد ع، ب... 
7. MOH report on tuberculosis in Iraq, 1999. TB annual report. Baghdad, Iraq, Ministry of Health, 1999

8. Fox W. Self-administration of medicaments. A review of published work and study of the problem. Bulletin of the International Union against Tuberculosis, 1962, 32:307-31.

9. Rouillon A. Problems raised by the organization of an efficient ambulatory treatment for tuberculous patients. Bulletin of the International Union against Tuberculosis, 1972, 47:72-87.

10. Wilkinson D. Eight years of tuberculosis research in Hlabisa-what have we learned? South African medical journal, 1999, 89(2):155-9.

11. Weis SE. Universal directly observed therapy. A treatment strategy for tuberculosis. Clinics in chest medicine, 1994, 18:155-63.

12. Iseman MD. Directly observed therapy, patient education and combined drug formulations: complementary, not alter- native, strategy in tuberculosis control. Tubercle and lung disease, 1996, 77: 101.

13. Salomon $\mathrm{N}$ et al. Implementation of universal directly observed therapy at a New York City hospital and evaluation of an out-patient directly observed therapy program. International journal of tuberculosis and lung disease, 1997, 1:397404.

14. Caminero JA et al. Evaluation of a directly observed six months fully intermittent treatment regimen for tuberculosis in patients suspected of poor compliance. Thorax, 1996, 51:1130-3.

15. Jin BW et al. The impact of intensified supervisory activities on tuberculosis treatment. Tubercle and lung disease, 1993, 74:267-72.

16. China Tuberculosis Control Collaboration. Results of directly observed shortcourse chemotherapy in 112,842 Chinese patients with smear-positive tuberculosis. Lancet, 1996, 347:358-62. 